\title{
Relation entre l'excrétion urinaire d'allantoine et le flux duodénal d'acide ribonucléique
}

\author{
F. LAURENT, B. VIGNON
}

Département de Sciences animales, E.N.S.A.I.A.,

2, Av. de la Foret de Haye, 54500 Vandœuvre, France.

Summary. The relationship between allantoin excretion and duodenal RNA flows was studied. Between 73 and $85 \%$ of the RNA disappeared in the gut. Urinary allantoin nitrogen represented between 32 and $76 \%$ of the amount of RNA nitrogen digested. Purine nitrogen valorization could then be estimated as between 40 to $60 \%$.

La mesure de l'excrétion urinaire d'allantoïne a été proposée comme un indicateur de l'intensité de la synthèse et de la dégradation des acides nucléiques microbiens dans le tube digestif des ruminants. Toutefois, les mesures du taux de conversion de l'azote nucléique en azote de l'allantoïne ont été surtout effectuées avec des surcharges duodénales en acide ribonucléique (ARN) pur (Antoniewicz et al., 1980). Nos essais ont été réalisés pour caractériser la relation entre le flux duodénal d'ARN et l'excrétion urinaire d'allantoïne avec des rations usuelles.

Matériel et méthodes. Deux béliers adultes castrés à l'entretien et deux chèvres en lactation porteurs de canules simples du rumen et du duodénum sont placés en cage à digestibilité. Pendant 30 jours de mesures, les animaux reçoivent, à volonté en 2 repas, du fourrage vert (Ray-grass anglais), de l'ensilage de maïs ou une ration foin + pulpes de betteraves + concentrés (tabl. 1).

TABL. 1. - Flux d'acide ribonucléique dans le duodénum et excrétion d'allantoine urinaire.

\begin{tabular}{|c|c|c|c|c|c|c|}
\hline \multirow[b]{2}{*}{ Animaux } & \multirow[b]{2}{*}{ Régimes } & \multicolumn{3}{|c|}{ Flux d'azote $\mathrm{mg} / \mathrm{j}$} & \multirow{2}{*}{$\frac{\text { ARN digéré }}{\%}$} & \multirow{2}{*}{$\frac{N \text { allantoine }}{\begin{array}{c}\% \text { N ARN } \\
\text { digéré }\end{array}}$} \\
\hline & & $\begin{array}{c}\text { ARN } \\
\text { duodénum }\end{array}$ & $\begin{array}{l}\text { ARN } \\
\text { fécal }\end{array}$ & Allantoïne & & \\
\hline $\begin{array}{l}\text { Chèvres } \\
\text { en lactation }\end{array}$ & $\begin{array}{l}\text { Pulpes betteraves } \\
+ \text { foin }+ \text { orge } \\
+ \text { tourteau soja } \\
\text { Ray grass }+ \text { orge }\end{array}$ & $\begin{array}{l}2390 \\
2563 \\
1728 \\
2342\end{array}$ & $\begin{array}{l}604 \\
661 \\
251 \\
344\end{array}$ & $\begin{array}{r}656 \\
702 \\
471 \\
1158\end{array}$ & $\begin{array}{l}73,2 \\
74,2 \\
85,5 \\
82,1\end{array}$ & $\begin{array}{l}36,7 \\
36 ; 9 \\
32,0 \\
57,8\end{array}$ \\
\hline Chèvre tarie & Ensilage maïs & 1564 & 265 & 614 & 76,5 & 47,3 \\
\hline $\begin{array}{l}\text { Moutons } \\
\text { à l'entretien }\end{array}$ & $\begin{array}{l}\text { Ray grass } \\
\text { Ray grass } \\
\text { Ensilage maïs }\end{array}$ & $\begin{array}{l}1758 \\
1635 \\
1306\end{array}$ & $\begin{array}{l}314 \\
385 \\
259\end{array}$ & $\begin{array}{l}726 \\
948 \\
563\end{array}$ & $\begin{array}{l}85,3 \\
80,2 \\
83,0\end{array}$ & $\begin{array}{l}50,3 \\
75,8 \\
53,7\end{array}$ \\
\hline
\end{tabular}

Les flux dans le duodénum sont mesurés avec 2 marqueurs, le polyéthylèneglycol (PEG 4000) et l'oxyde de chrome. Les marqueurs (100 ml de PEG et $2 \mathrm{~g}$ de papier chromé par jour) sont directement introduits dans le rumen, au moment des repas, pendant 20 jours. Les prélèvements de jus de duodénum et la détermination des marqueurs sont réalisés dans les conditions décrites antérieurement 
(Laurent et al., 1986). Le flux moyen est calculé en admettant que les taux de recouvrement des marqueurs sont identiques au niveau du duodénum et des fécès. Des échantillons individuels de fécès frais $(100 \mathrm{~g} / \mathrm{j})$ sont prélevés pendant les 7 jours précédant la mesure des flux. Les teneurs en ARN dans les jus de duodénum et les fécès congelés sont déterminés selon les propositions de Ben Ghedalia (1981). La teneur en allantoïne des urines est mesurée (Vogels et Van Der Drift, 1970) sur les échantillons individuels prélevés pendant 7 jours.

Résultats et discussion. Au niveau du duodénum le flux quotidien d'azote ARN, compris entre 1,3 et $2,6 \mathrm{~g}$, est fortement lié à la quantité de matière organique ingérée ( $r=0,782$ pour 8 séries de mesures) (tabl. 1). La digestibilité apparente dans l'intestin de l'azote ARN varie entre 73 et $85 \%(\bar{m}=$ $80,0 \pm 4,8)$, valeurs qui recoupent différentes mesures rapportées par MacAllan (1982).

L'excrétion urinaire d'azote de l'allantoine représente en moyenne environ la moitié de la quantité d'azote ARN digéré. Cette valeur est légèrement supérieure à celle $(0,4)$ enregistrée par Antoniewicz et al. (1980). Le rapport azote de l'allantoïne/azote ARN digéré $(R)$ est peu différent lorsque chèvre et mouton, à l'entretien, reçoivent le même régime (ensilage de maïs). La très forte variabilité de $R$, compris entre 0,32 et 0,76 , pourrait s'expliquer par les différences entre animaux, par les multiples facteurs, (état physiologique, niveau de production) jouant sur l'excrétion d'allantoïne (Laurent et Vignon, 1983). Le fait que $R$ soit en moyenne plus élevé chez les moutons à l'entretien ( $R=0,60, n=3)$ que chez les chèvres en lactation ( $R=0,40, n=4$ ) pourrait renforcer l'hypothèse d'une meilleure valorisation de l'azote ARN chez les animaux ayant des besoins élevés.

En retenant un flux duodénal d'ARN 2 fois supérieur au flux d'ADN, avec un rapport $\mathrm{N}$ purique/ $\mathrm{N}$ pyrimidique égal à 2, l'azote ARN peut être considéré comme un bon estimateur de l'azote purique. Cette première estimation devrait être corrigée pour tenir compte de l'excrétion d'allantoïne endogène mais aussi de l'excrétion de déchets puriques sous forme d'acide urique ou de purines libres.

Antoniewicz A. Heinemann W. W., Hanks E. M., 1980. J. agric Sci. Camb., 95, 395-400. Ben Ghedalia D., 1981. J. Dairy Sci, 64, 2422-2425.

Laurent F., Vignon B., 1983. Arch. Tierernähr., 33, 671-681.

Laurent F., Brun-Bellut J., Vignon B., 1986. Reprod. Nutr. Dévelop., 26, 317-318.

MacAllan A. B., 1982. Proc. Nutr. Soc., 41, 309-317.

Vogels G. D., Van Der Drift C., 1970. Anal. Biochem., 33, 143-157. 